\title{
Vitamin D supplementation as a potential cause of U-shaped associations between vitamin $D$ levels and negative health outcomes: a decision tree analysis for risk of frailty
}

Gotaro Kojima ${ }^{1 *}$, Steve lliffe ${ }^{1}$ and Marianne Tanabe ${ }^{2}$

\begin{abstract}
Background: A recent controversy in vitamin D research is a "U-shaped association", with elevated disease risks at both high and low 25-hydroxyvitamin D $(25(\mathrm{OH}) \mathrm{D})$ levels.

Methods: This is a cross-sectional study of 238 male nursing home veterans in Hawaii. Classification and regression tree (CART) analysis identified groups based on $25(\mathrm{OH})$ D and vitamin D supplementation for frailty risk.

Characteristics were examined and compared across the groups using logistic regression and receiver operating characteristic (ROC) curve analyses.

Results: CART analysis identified three distinct groups: vitamin D supplement users ( $n=86)$, non-users with low vitamin $\mathrm{D}(n=55)$, and non-users with high vitamin $\mathrm{D}(n=97)$. Supplement users were the most frail, but had high mean $25(\mathrm{OH})$ D of $26.6 \mathrm{ng} / \mathrm{mL}$, which was compatible with $27.1 \mathrm{ng} / \mathrm{mL}$ in non-users with high vitamin $\mathrm{D}$, while mean $25(\mathrm{OH}) \mathrm{D}$ of non-users with low vitamin D was $11.7 \mathrm{ng} / \mathrm{mL}$. Supplement users and non-users with low vitamin D were significantly more likely to be frail (odds ratio $(\mathrm{OR})=9.90,95 \% \mathrm{Cl}=2.18-44.86, p=0.003 ; \mathrm{OR}=4.28,95 \% \mathrm{Cl}=1.44-12$. $68, p=0.009$, respectively), compared with non-users with low vitamin D. ROC curve analysis showed the three groups significantly predicted frailty (area under the curve $=0.73$ ), with sensitivity of $64.4 \%$ and specificity of $76.7 \%$, while 25 $(\mathrm{OH}) \mathrm{D}$ did not predict frailty.
\end{abstract}

Conclusions: In these nursing home veterans, vitamin D supplement users were the most frail but with high $25(\mathrm{OH})$ D. This can potentially be a cause of U-shaped associations between vitamin D levels and negative health outcomes.

Keywords: Frailty, Vitamin D, Vitamin D deficiency, Vitamin D supplementation, Nursing home

\section{Background}

Vitamin D deficiency is prevalent worldwide and has been recognized as a public health problem [1]. Low vitamin D has been extensively studied and shown to be associated with various negative health outcomes, such as osteoporosis, fracture, muscle weakness, falls, autoimmune diseases, and cardiovascular diseases [2]. Optimizing deficient vitamin D levels with supplementation can result in mostly

\footnotetext{
* Correspondence: gotarokojima@yahoo.co.jp

${ }^{1}$ Department of Primary Care and Population Health, University College London (Royal Free Campus), Rowland Hill Street, London NW3 2PF, UK

Full list of author information is available at the end of the article
}

favorable results, although definitive evidence from welldesigned randomized controlled clinical trials is lacking [3]. In light of the accumulating evidence on the beneficial effects of vitamin D supplementation and its relatively safe side-effect profile, vitamin D supplementation has been recommended by multiple authorities and guidelines [4-6].

One of the recent controversies in vitamin D research is a "U-shaped association", [7-9] in which both high and low levels of vitamin $\mathrm{D}$ are associated with elevated disease risks [7]. Regarding all-cause mortality, most observational population-based studies have shown that low vitamin $\mathrm{D}$ predicted premature death, which is supported 
by recent meta-analyses [10-13]. However, there were a considerable number of studies that showed U-shaped or reverse J-shaped associations between vitamin $\mathrm{D}$ and mortality [14-20]. One of the meta-analysis studies showed the possibility that mortality risk may become higher again at a serum 25-hydroxyvitamin D (25 (OH) D) level of $112.5 \mathrm{nmol} / \mathrm{l}$ or more [12]. The association between high vitamin $\mathrm{D}$ and high mortality appears counterintuitive and the underlying mechanisms are unknown. Criticisms of this paradoxical finding were that it was due to chance, [7] a lack of adequate adjustment, [8] an analytical bias due to serum vitamin D assays, [7] a small number of the highest serum vitamin D group, [18] or vitamin D intoxication [21].

Use of vitamin D supplementation may be a cause of increased disease risks at high vitamin $\mathrm{D}$ levels and can create U-shaped associations [22]. The Newcastle 85+ Study prospectively followed 775 men and women aged 85 or older over 6 years and examined all-cause mortality according to baseline $25(\mathrm{OH}) \mathrm{D}$ levels [13]. Compared with the middle $25(\mathrm{OH}) \mathrm{D}$ group, the highest and lowest $25(\mathrm{OH}) \mathrm{D}$ groups had non-significantly increased mortality risks (adjusted hazard ratio $[\mathrm{HR}]=1.25,95 \%$ confidence interval $[\mathrm{CI}]=0.97-1.63 ; \mathrm{HR}=1.10,95 \%$ $\mathrm{CI}=0.85-1.42$, respectively). After excluding 150 vitamin $\mathrm{D}$ supplement users, the mortality risk for the highest 25 $(\mathrm{OH}) \mathrm{D}$ group decreased by $16 \%$ (adjusted $\mathrm{HR}=1.05$, 95\% $\mathrm{CI}=0.73-1.53)$ whereas the mortality risk for the lowest $25(\mathrm{OH})$ D group increased (adjusted HR $=1.22,95 \%$ $\mathrm{CI}=0.93-1.60)$ [13]. It is speculated that the supplement users were at high risk with high $25(\mathrm{OH}) \mathrm{D}$, likely due to the supplements, which led to the increased mortality risk of the highest $25(\mathrm{OH}) \mathrm{D}$ group. Another meta-analysis study showed that the mortality risk for low $25(\mathrm{OH}) \mathrm{D}$ was significantly lower among studies with prevalence of vitamin D supplement use of more than $10 \%$ compared with studies with less than $10 \%$ ( $\mathrm{p}$ for meta-regression analysis $<0.05$ ), [11] which suggests that vitamin D supplementation attenuated inverse association between vitamin D and mortality, possibly by increasing $25(\mathrm{OH})$ D of high-mortality-risk participants.

In order to further investigate how vitamin D supplementation affects associations between vitamin D status and health outcomes, we explored use of vitamin D supplementation and serum $25(\mathrm{OH}) \mathrm{D}$ in relation to frailty, using a cohort of frail nursing home residents [23] among whom prevalence of both vitamin D supplement use and vitamin D deficiency are high. Our hypothesis was that those on a vitamin D supplement were highly frail even though serum vitamin D levels were elevated by supplements. They could be included in "high" vitamin D groups along with healthier vitamin D sufficient non-supplement users, leading to the seemingly paradoxically high risks of various health outcomes in those with high vitamin $\mathrm{D}$.

\section{Methods}

\section{Study design, setting, and population}

This cross-sectional study was conducted at a Veterans Affairs nursing home in Honolulu, Hawaii, providing rehabilitation, skilled-nursing care, intermediate care, respite care, and hospice/palliative care for veterans. The study participants were all male veterans admitted to the study nursing home except for those admitted for hospice/palliative care, from 1st of January 2011 to 31st of December 2012. The data were anonymised and collected by a retrospective chart review. This study was approved by the Institutional Review Boards of Veterans Affairs Pacific Islands Health Care System. The study design, setting, and population have been described in detail elsewhere $[24,25]$.

\section{Predictor variables - vitamin D supplementation and vitamin D level}

Serum total $25(\mathrm{OH}) \mathrm{D}$ was measured for all veterans on nursing home admission as a part of initial assessment. The information on vitamin D supplementation was obtained from transfer summaries, discharge summaries, outpatient clinic notes, or history taken from veterans or family. Various dosage, frequency, and duration were observed for vitamin D supplementation, from one multivitamin tab a day to 50,000 IU of ergocalciferol three times weekly. Use of vitamin D supplementation was calculated as a mean daily dosage of any vitamin D supplement over the previous 1 month and categorized into four groups: no supplement, 1-400 IU/day, 401-800 IU/ day, or $\geq 801 \mathrm{IU} /$ day.

\section{Outcome variable - frailty}

Frailty has been described as a state of reduced physiological reserve due to age related accumulation of multisystem impairments [26]. As people become frailer, they are more predisposed to increased risks of various adverse health outcomes, including falls, fractures, hospitalization, nursing home placement, disability, poor quality of life, and dementia [27-34]. Therefore frailty was considered as a good surrogate marker of biological aging [35]. In this study, frailty was measured by using a deficit accumulation model of the Frailty Index (FI) [35] FI is calculated from a variety of health deficits that usually include symptoms, signs, comorbidities, and disabilities that are biologically sensible, accumulate with age, do not saturate too early, and cover a range of systems [36]. Although FI does not require the same number of deficits or the same set of deficits, it is recommended to include at least 30 deficits [36]. We constructed FI based on 34 deficits including 12 chronic diseases, 9 psychological symptoms, 6 functional disabilities, 3 gait/fall-related problems, 2 cognitive symptoms, 1 obesity, and 1 pain symptom. (see the Additional file 1 for detail) [36, 
37]. Although FI is a continuous score and not meant to be dichotomized, we used an empirical cut-point to define frailty as FI $>=0.25$ [38].

\section{Covariates}

Demographic data collected on admission were age, body mass index, ethnicity (White, Asian/Pacific Islander, or other), education, smoking, alcohol, place where veterans came from (home, acute care hospitals, or other nursing homes), season and reason for admission (rehabilitation, non-rehabilitation skilled-nursing care, intermediate care, or respite care).

\section{Statistical analysis}

The classification and regression tree (CART) analysis [39] is a non-parametric classification technique that can deal with multiple predictors of both continuous and categorical data. It builds a decision tree by recursive partitioning to best explain the risk estimate of the dependent variable. This method has often been used for data mining and it was considered to be appropriate for the exploratory nature of this study. We used this method to split the cohort based on two variables: use of vitamin D supplementation and $25(\mathrm{OH}) \mathrm{D}$, into progressively smaller and more homogeneous subgroups with highest discriminative ability of identifying frailty risk. The minimum number of cases in a node was set at $23,1 / 10$ of the entire cohort, and the minimum change in improvement was set at 0.001. Ten-fold cross-validation was performed. The subgroups by the CART analysis were compared for the characteristics using a one-way analysis of variance (ANOVA) for continuous variables and a chi-square test for categorical variables. Correlation coefficient was examined using Spearman's rho between $25(\mathrm{OH}) \mathrm{D}$ and the FI in the entire cohort as well as supplement users and nonusers. Relative likelihood of frailty of each CART group compared with the entire cohort was calculated. Univariate logistic regression models were used to examine risk of frailty for the CART groups and other characteristics. The CART groups were further examined for independent risk of frailty using a multivariate logistic regression model adjusted for variables which were significant in the univariate logistic regression models. Frailty risk discrimination by the CART analysis was assessed using the receiver operating characteristic (ROC) curve analysis and the area under the ROC curve (AUC), and was compared with that by $25(\mathrm{OH})$ $\mathrm{D}$ as a continuous variable.

Among the supplement users, the characteristics were compared using a one-way ANOVA for continuous variables and a chi-square test for categorical variables according to the dosage of the supplement.
All statistical analyses were conducted using IBM SPSS Statistics (version 20, IBM Corporation, Armonk, NY, USA), and two-sided $p$ value of $<0.05$ was considered statistically significant.

\section{Results}

There were a total of 302 male veterans admitted to the study nursing home during 2011 and 2012. Of those, 61 veterans who did not have $25(\mathrm{OH})$ D measured within 7 days of admission and 3 veterans who missed more than $30 \%$ of deficits for constructing FI were excluded, leaving 238 veterans $(78.8 \%)$ as a final sample. There were no significant differences in mean age, mean $25(\mathrm{OH})$ D level, BMI, smoking, alcohol use and FI between those included $(n=238)$ and those excluded $(n=64)$. Those excluded had slightly but significantly longer duration of education compared with those included (13.7 v 13.0 years).

\section{Decision tree analysis}

Figure 1 displays a decision tree of the CART analysis. The cohort was initially divided into two groups: those on vitamin D supplement of any dosage (1-400 IU/day, 401$800 \mathrm{IU} /$ day, or $\geq 801 \mathrm{IU} /$ day, vitamin D supplement users, $n=86$ ) and those without vitamin $\mathrm{D}$ supplement (nonusers, $n=152$ ). Non-users were further divided based on $25(\mathrm{OH}) \mathrm{D}$ with a cut-off point of $17.5 \mathrm{ng} / \mathrm{mL}$ into two groups: non-users with low vitamin $\mathrm{D}$ level $(n=55)$ and non-users with high vitamin $\mathrm{D}$ level $(n=97)$. The crossvalidation showed the same risk estimate. As a supplementary analysis the CART analysis was repeated using the FI as a continuous outcome variable, which showed very similar results (data not shown).

\section{Cohort characteristics}

Table 1 presents demographic characteristics of the entire cohort $(N=238)$. The mean age was 73.4 years. The mean Frailty Index (FI) was 0.39 and $87.4 \%(n=208)$ had frailty ( $\mathrm{FI}>=0.25)$. The mean $25(\mathrm{OH}) \mathrm{D}$ was $23.4 \mathrm{ng} / \mathrm{mL}$, ranging $4-53 \mathrm{ng} / \mathrm{mL}$, and $37.4 \%(n=89)$ had $25(\mathrm{OH}) \mathrm{D}<20 \mathrm{ng} / \mathrm{mL}$.

The characteristics were compared across three groups by CART analysis: supplement users $(n=86,36.1 \%)$, non-users with low vitamin $\mathrm{D}(n=55,23.1 \%)$, and nonusers with high vitamin $\mathrm{D}(n=97,40.8 \%)$ (Table 1$)$. The mean FI and prevalence of frailty were both significantly different across the groups, with supplement users being the most frail and non-users with high vitamin $\mathrm{D}$ being the least frail (mean FI: $0.43,0.41$, and 0.35 , respectively. Frailty prevalence: $97.7,90.9$, and $76.3 \%$, respectively. Both $p<0.001)$. Supplement users and non-users with high vitamin D had significantly higher $25(\mathrm{OH})$ D, 26.6 and $27.1 \mathrm{ng} / \mathrm{mL}$, respectively, than non-users with low vitamin $\mathrm{D}, 11.7 \mathrm{ng} / \mathrm{mL}$. While FI and $25(\mathrm{OH}) \mathrm{D}$ were not significantly correlated in the entire cohort and 


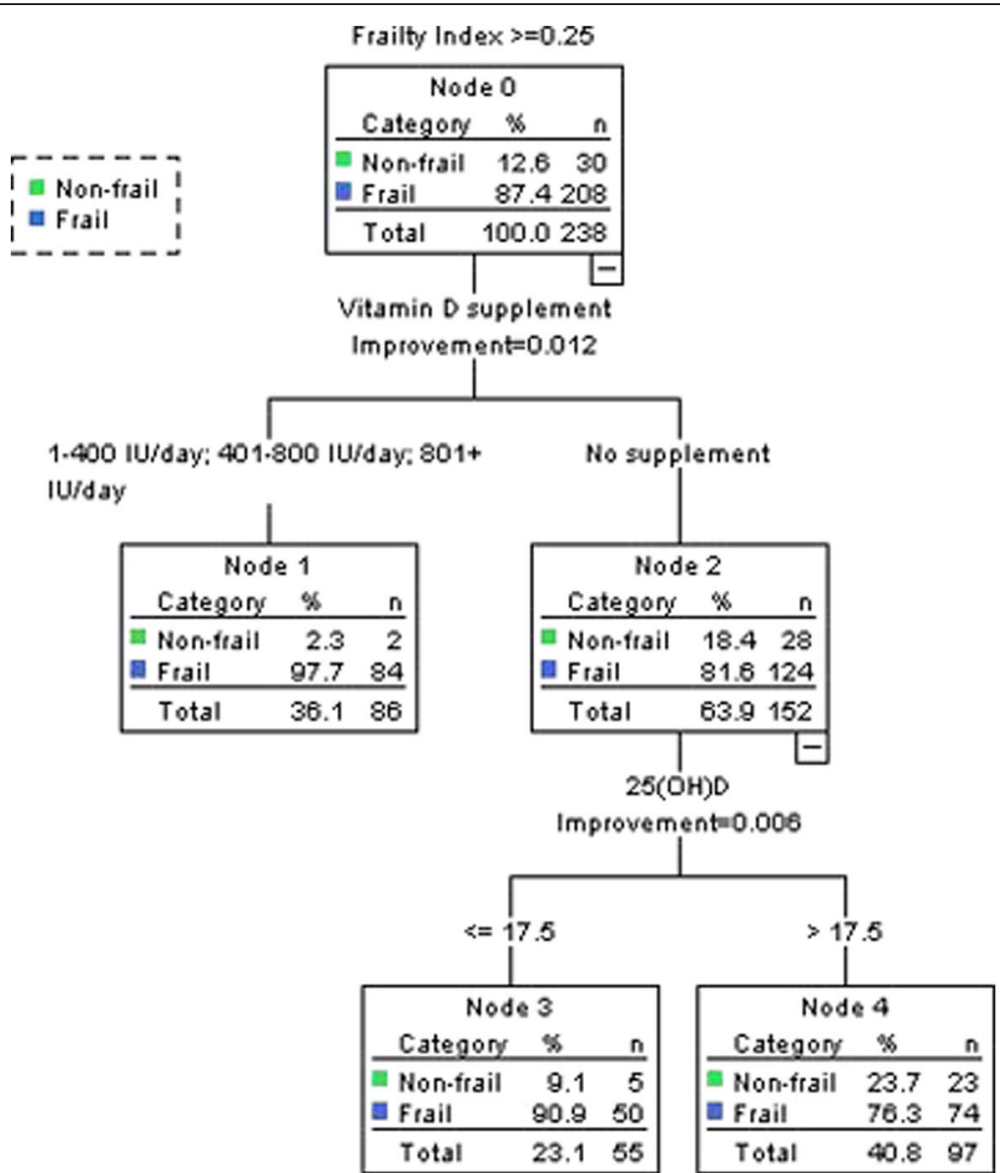

Fig. 1 A decision tree by classification and regression tree analysis based on use of vitamin $\mathrm{D}$ supplement and 25-hydroxyvitamin $\mathrm{D}(25(\mathrm{OH}) \mathrm{D})$ among 238 male veterans in a nursing home. $25(\mathrm{OH})$ D: 25-hydroxyvitamin D

supplement users $(r=-0.10$ and -0.05 , respectively), there was a significant inverse correlation between FI and $25(\mathrm{OH}) \mathrm{D}$ in non-users $(r=-0.19, p=0.02)$.

Table 2 shows univariate and age-adjusted logistic regression models used to assess risk of frailty ( $\mathrm{FI} \geq 0.25$ ). In unadjusted models, supplement users and non-users with low vitamin $\mathrm{D}$ were significantly more likely to be frail (Odds ratio $[\mathrm{OR}]=13.05,95 \% \mathrm{CI}=2.98-57.25$, $p=0.001$; OR $=3.11,95 \% \mathrm{CI}=1.11-8.72, p=0.03$, respectively), with non-users with high vitamin $\mathrm{D}$ as a reference. In age-adjusted models, the risk of frailty for supplement users and non-users with low vitamin D remained significant after adjusting for age $(\mathrm{OR}=9.90$, $95 \% \mathrm{CI}=2.18-44.86, p=0.003 ; \mathrm{OR}=4.28,95 \%$ $\mathrm{CI}=1.44-12.68, p=0.009$, respectively).

Figure 2 shows an ROC curve analysis showing that CART analysis groups accurately classified risk of frailty among the entire cohort, with AUC of 0.73 $(95 \% \mathrm{CI}=0.65-0.82, p<0.001)$. Being on a vitamin $\mathrm{D}$ supplement, compared with no use, has sensitivity of $64.4 \%$ and specificity of $76.7 \%$. Conversely, $25(\mathrm{OH})$ D was not a significant predictor of frailty (AUC $=0.56$
95\% CI $=0.46-0.66, p=0.32$ ). After removing supplement users in order to exclude effects of vitamin D supplementation, ROC curve analysis for $25(\mathrm{OH}) \mathrm{D}$ was repeated only among non-users $(n=152)$. This repeated analysis showed that $25(\mathrm{OH}) \mathrm{D}$ significantly predicted frailty among non-users, with AUC of 0.62 (95\% $\mathrm{CI}=0.52-0.73, p=0.04$ ) (Figure not shown).

Among 86 supplement users, the dosages of vitamin D supplementation were $1-400 \mathrm{IU} /$ day $(n=27,31.4 \%)$, 401-800 IU/day ( $n=38,44.2 \%)$, and $\geq 801 \mathrm{IU} /$ day ( $n=21,25.3 \%$ ). Table 3 compares the three groups and shows that higher dosage of vitamin $\mathrm{D}$ supplementation was significantly associated with higher $25(\mathrm{OH}) \mathrm{D}(\mathrm{p}$ for trend $=0.003$ ) and higher body mass index $(p=0.05)$. Although statistical significance was not reached, those on higher dosage of supplementation were more likely from home and less likely from acute care hospitals $(p=0.06)$.

\section{Discussion}

In the current study, three distinct subgroups were successfully identified based on use of vitamin D 
Table 1 Characteristics according to three groups based on vitamin D level and supplement use

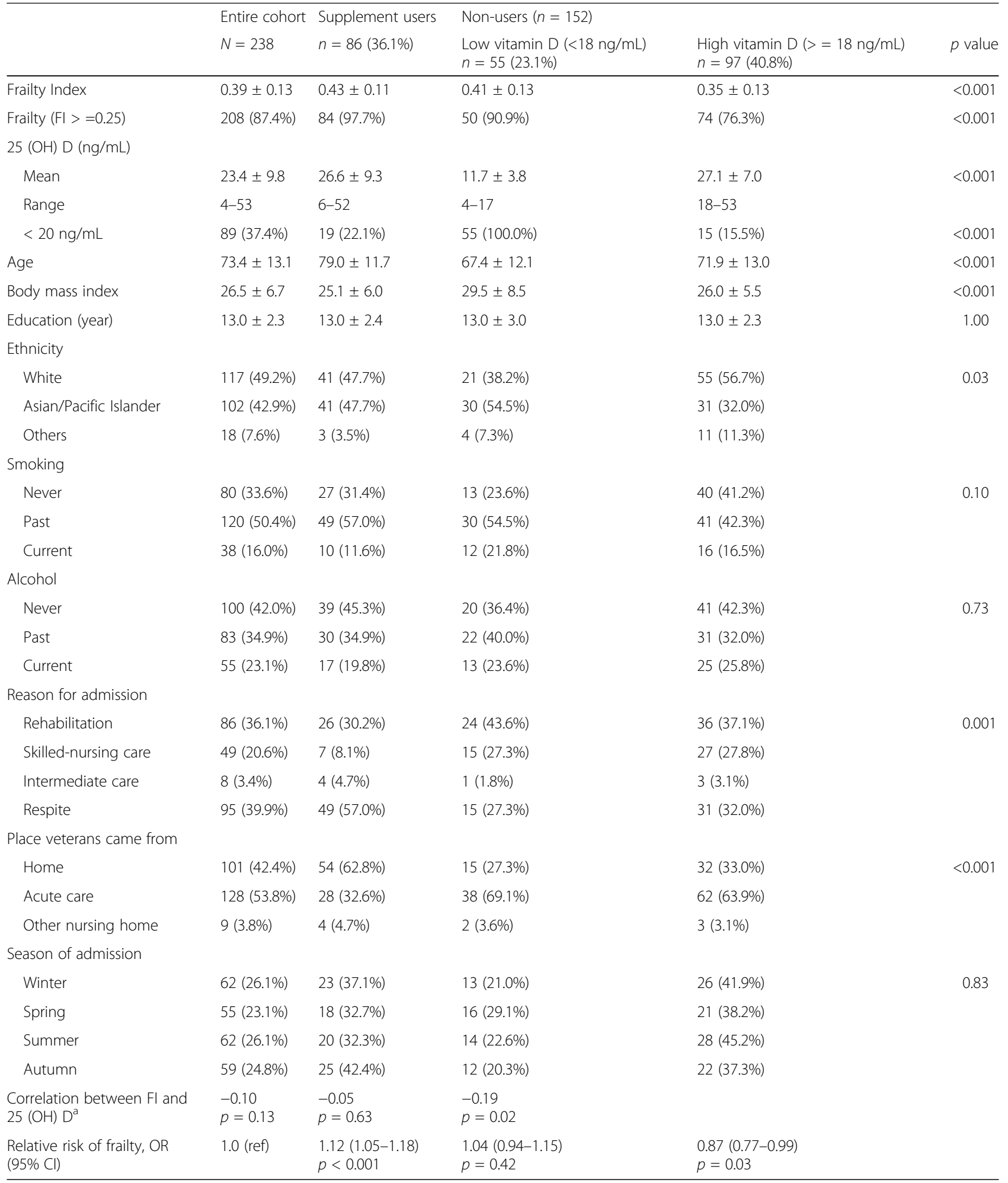

Analysis of variance for continuous variables and chi-square test for categorical variables mean \pm Standard deviation, $\mathrm{n}(\%)$ $25(\mathrm{OH}) \mathrm{D} 25$-hydroxyvitamin D level, $95 \% \mathrm{Cl} 95 \%$ confidence interval, $\mathrm{Fl}$ Frailty Index, OR Odds ratio

${ }^{\text {a }}$ Spearman's correlation coefficient in supplement users and non-users 
Table 2 Univariate and age-adjusted logistic regression models for frailty

\begin{tabular}{|c|c|c|c|c|}
\hline \multirow[b]{2}{*}{ Factors } & \multicolumn{2}{|l|}{ Unadjusted } & \multicolumn{2}{|l|}{ Age-adjusted } \\
\hline & Odds Ratio $(95 \% \mathrm{Cl})$ & $p$ value & Odds Ratio (95\% Cl) & $p$ value \\
\hline \multicolumn{5}{|l|}{ Three groups by CART analysis } \\
\hline Non-user with high $25(\mathrm{OH}) \mathrm{D}$ & 1.0 (ref) & - & 1.0 (ref) & - \\
\hline Non-user with low $25(\mathrm{OH}) \mathrm{D}$ & $3.11(1.11-8.72)$ & 0.03 & $4.28(1.44-12.68)$ & 0.009 \\
\hline Supplement user & $13.05(2.98-57.25)$ & 0.001 & $9.90(2.18-44.86)$ & 0.003 \\
\hline $25(\mathrm{OH}) \mathrm{D}(\mathrm{ng} / \mathrm{mL})$ & $0.98(0.95-1.02)$ & 0.39 & - & - \\
\hline Age (years) & $1.06(1.03-1.10)$ & $<0.001$ & - & - \\
\hline Body mass index & $1.01(0.95-1.07)$ & 0.84 & - & - \\
\hline Education (year) & $0.90(0.76-1.08)$ & 0.26 & - & - \\
\hline \multicolumn{5}{|l|}{ Ethnicity } \\
\hline White & 1.0 (ref) & - & - & - \\
\hline Asian/PI & $2.13(0.92-4.92)$ & 0.08 & - & - \\
\hline Others & $3.51(0.44-27.87)$ & 0.24 & - & - \\
\hline \multicolumn{5}{|l|}{ Smoking } \\
\hline Never & 1.0 (ref) & - & - & - \\
\hline Past & $1.59(0.68-3.74)$ & 0.29 & - & - \\
\hline Current & $0.94(0.32-2.73)$ & 0.91 & - & - \\
\hline \multicolumn{5}{|l|}{ Alcohol } \\
\hline Never & 1.0 (ref) & - & - & - \\
\hline Past & $1.12(0.45-2.81)$ & 0.81 & - & - \\
\hline Current & $0.70(0.27-1.78)$ & 0.45 & - & - \\
\hline
\end{tabular}

$25(\mathrm{OH}) \mathrm{D}$ 25-hydroxyvitamin D level, 95\% Cl 95\% confidence interval, CART Classification and regression tree

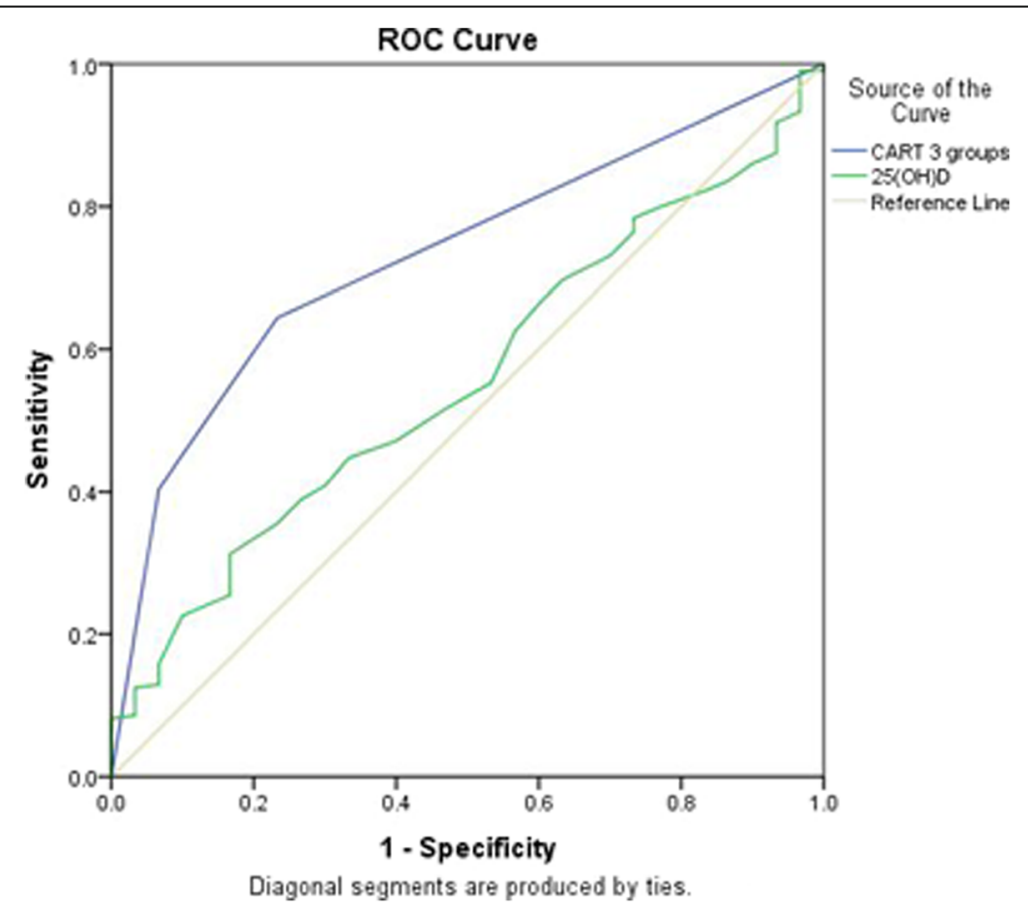

Fig. 2 Receiver operating characteristic (ROC) curve analyses for risk of frailty predicted by the classification and regression tree (CART) analysis groups (blue line) and 25-hydroxyvitamin D (25 (OH) D) level (green line). $25(\mathrm{OH}) \mathrm{D}$ : Serum total 25-hydroxyvitamin D. CART: Classification and regression tree. Area under the ROC curve $(A \cup C)=0.73$ ( $95 \%$ confidence interval $(C I)=0.65-0.82, p<0.001)$ for CART analysis groups (blue line); $\mathrm{AUC}=0.56(95 \% \mathrm{Cl}=0.46-0.66, p=0.32)$ for $25(\mathrm{OH}) \mathrm{D}$ (green line) 
Table 3 Characteristics of vitamin D supplement users according to the dosage

\begin{tabular}{|c|c|c|c|c|c|}
\hline & $N=86$ & $\begin{array}{l}1-400 \mathrm{IU} / \text { day } \\
(n=27)\end{array}$ & $\begin{array}{l}401-800 \mathrm{IU} / \text { day } \\
(n=38)\end{array}$ & $\begin{array}{l}801+I U / \text { day } \\
(n=21)\end{array}$ & $p$ value \\
\hline Frailty Index & $0.43 \pm 0.11$ & $0.45 \pm 0.11$ & $0.40 \pm 0.09$ & $0.43 \pm 0.12$ & 0.59 \\
\hline Frailty (FI > =0.25) & $84(97.7 \%)$ & 25 (92.6\%) & 38 (100.0\%) & $21(100.0 \%)$ & 0.11 \\
\hline $25(\mathrm{OH}) \mathrm{D}(\mathrm{ng} / \mathrm{mL})$ & $26.6 \pm 9.3$ & $22.9 \pm 8.6$ & $26.8 \pm 8.4$ & $30.9 \pm 10.2$ & 0.003 \\
\hline Vitamin D deficiency & 19 (22.1\%) & $9(33.3 \%)$ & 7 (18.4\%) & $3(14.3 \%)$ & 0.10 \\
\hline Age & $79.0 \pm 11.7$ & $79.7 \pm 9.5$ & $80.9 \pm 11.1$ & $74.7 \pm 14.6$ & 0.17 \\
\hline Body mass index & $25.1 \pm 6.0$ & $23.9 \pm 4.7$ & $24.7 \pm 5.8$ & $27.5 \pm 7.5$ & 0.05 \\
\hline Education (year) & $13.0 \pm 2.4$ & $13.1 \pm 1.8$ & $12.7 \pm 2.7$ & $13.4 \pm 2.7$ & 0.72 \\
\hline \multicolumn{6}{|l|}{ Ethnicity } \\
\hline White & $41(47.7 \%)$ & $13(48.1 \%)$ & $22(59.5 \%)$ & $6(28.6 \%)$ & \multirow[t]{3}{*}{0.28} \\
\hline Asian/PI & $41(47.7 \%)$ & $13(48.1 \%)$ & $14(37.8 \%)$ & $14(66.7 \%)$ & \\
\hline Others & $3(3.5 \%)$ & $1(3.7 \%)$ & $1(2.7 \%)$ & $1(4.8 \%)$ & \\
\hline \multicolumn{6}{|l|}{ Reason for admission } \\
\hline Rehabilitation & $26(30.2 \%)$ & $13(48.1 \%)$ & $8(21.1 \%)$ & $5(23.8 \%)$ & \multirow[t]{4}{*}{0.11} \\
\hline Skilled-nursing care & $7(8.1 \%)$ & $0(0.0 \%)$ & $5(13.2 \%)$ & $2(9.5 \%)$ & \\
\hline Intermediate care & $4(4.7 \%)$ & $2(7.4 \%)$ & $2(5.3 \%)$ & $0(0.0 \%)$ & \\
\hline Respite & 49 (57.0\%) & $12(44.4 \%)$ & $23(60.5 \%)$ & $14(66.7 \%)$ & \\
\hline \multicolumn{6}{|c|}{ Place veterans came from } \\
\hline Home & $54(62.8 \%)$ & $12(44.4 \%)$ & $26(68.4 \%)$ & $16(76.2 \%)$ & \multirow[t]{3}{*}{0.06} \\
\hline Acute care & $28(32.6 \%)$ & $14(51.9 \%)$ & $11(28.9 \%)$ & $3(14.3 \%)$ & \\
\hline other nursing home & $4(4.7 \%)$ & $1(3.7 \%)$ & $1(2.6 \%)$ & $2(9.5 \%)$ & \\
\hline \multicolumn{6}{|l|}{ Smoking } \\
\hline Never & $27(31.4 \%)$ & $6(22.2 \%)$ & $14(36.8 \%)$ & $7(33.3 \%)$ & \multirow[t]{3}{*}{0.75} \\
\hline Past & $49(57.0 \%)$ & $18(66.7 \%)$ & $20(52.6 \%)$ & $11(57.0 \%)$ & \\
\hline Current & $10(11.6 \%)$ & $3(11.1 \%)$ & $4(10.5 \%)$ & $3(14.3 \%)$ & \\
\hline \multicolumn{6}{|l|}{ Alcohol } \\
\hline Never & $39(45.3 \%)$ & $11(40.7 \%)$ & $18(47.4 \%)$ & $10(47.6 \%)$ & \multirow[t]{3}{*}{0.82} \\
\hline Past & $30(34.9 \%)$ & $11(40.7 \%)$ & $11(28.9 \%)$ & $8(38.1 \%)$ & \\
\hline Current & $17(19.8 \%)$ & $5(18.5 \%)$ & $9(23.7 \%)$ & $3(14.3 \%)$ & \\
\hline
\end{tabular}

One-way ANOVA for continuous variables ( $\mathrm{p}$ for trend) and chi-square test for categorical variables. mean \pm standard deviation, $\mathrm{n}(\%)$

supplementation and $25(\mathrm{OH})$ D using the CART analysis. Taking vitamin D supplementation was the strongest frailty risk discriminative factor, and supplement users were found to have multiple distinguishable features. They were almost all frail, with the highest prevalence of $97.7 \%$ (84/86) among the three subgroups, but had high mean $25(\mathrm{OH}) \mathrm{D}$ of $26.6 \mathrm{ng} / \mathrm{mL}$, which was compatible with non-users with high vitamin $\mathrm{D}$ (27.1 ng/mL). Among supplement users, $25(\mathrm{OH}) \mathrm{D}$ was not correlated with FI, while there was a significant correlation among non-users.

In light of these findings, we speculate that vitamin D supplement users are a group of highly frail older people with paradoxically high $25(\mathrm{OH})$ D levels. This discrepancy between $25(\mathrm{OH}) \mathrm{D}$ and frailty may result from the fact that vitamin D supplementation can quickly correct low $25(\mathrm{OH})$ D [40]; however, it may take longer to see positive effects on mortality or other outcomes [11, 41]. One meta-analysis showed that vitamin D supplementation significantly decreased mortality only with follow-up longer than 3 years [41]. In addition, supplements increase $25(\mathrm{OH}) \mathrm{D}$ more efficiently in those with lower baseline $25(\mathrm{OH}) \mathrm{D},[42]$ which will further exacerbate the discrepancy. Therefore, frail supplement users are likely to remain at high risk of negative health outcomes even with optimized vitamin D status by supplementation, which could potentially confound the profiles and outcomes of the vitamin D-sufficient group. In observational studies, true associations of $25(\mathrm{OH}) \mathrm{D}$ with outcomes could be attenuated or reversed at high $25(\mathrm{OH})$ D levels, creating falsely null or U-shaped associations unless controlled properly for the use of vitamin D supplements. 
Vitamin D supplements have been used more and more commonly in general populations. According to NHANES, the use of dietary vitamin D supplements has increased among both men and women in most age groups from 1988 to 1994 to 2003-2006 [43]. This increase may be explained by several reasons. With guidelines and authorities advocating the importance of treating low vitamin D, clinicians more often check patients' serum vitamin D levels and prescribe vitamin D supplement for low vitamin D. Increasing sun protection for skin cancer prevention can also contribute to the increase in vitamin D supplementation. Due to growing media exposure regarding risks of low vitamin D levels, the general public has more awareness of the importance of vitamin D than ever. Furthermore, vitamin D supplements are inexpensive and readily available over the counter with almost no serious adverse effects, which further lowers the threshold for people to start the supplements. In this context, future vitamin $\mathrm{D}$ research should take into account the possibility of high prevalence of vitamin D supplementation in various populations, which may have significant confounding effects.

This study has some limitations and its findings must be interpreted with caution. First, it included a small number of only male veterans in a nursing home at a single facility in Hawaii, and the findings may not be entirely generalizable to other populations or to women. Second, some important information related to vitamin D status is missing, such as dietary vitamin D intake, sunlight exposure, or reasons for vitamin D supplementation. Third, we did not have information on what assay was used to measure $25(\mathrm{OH}) \mathrm{D}$ given that $25(\mathrm{OH}) \mathrm{D}$ levels vary according to the assay used [44]. Fourth, due to the small number of participants, we included those who had available data for at least $70 \%$ of the deficits, instead of $80 \%$, which is typically required for calculation of the FI [36]. Fifth, the multiple imputation could have been conducted for missing value of $25(\mathrm{OH})$ D. Lastly, the cross-sectional study design hinders assessing prospective associations and interactions among $25(\mathrm{OH})$ D, vitamin D supplementation, and health outcomes, as vitamin D supplementation may improve supplement users' overall health status and decrease the risks over years.

\section{Conclusion}

Three distinct groups were categorized from the study: 1) vitamin $D$ supplement users, 2) non-users with low vitamin $\mathrm{D}$, and 3) non-users with high vitamin D levels. This study shows that use of vitamin D supplements can potentially be a cause of paradoxical U-shaped associations between vitamin D levels and negative health outcomes, by creating a unique group of participants who are the most frail but have high $25(\mathrm{OH})$ D levels. This highlights the importance of identifying vitamin $\mathrm{D}$ supplement users and ideally obtaining information on the dosage and duration of the supplementation in order to better examine the true association between vitamin $\mathrm{D}$ and health outcomes, including frailty status, by controlling for vitamin D supplementation effects. Future studies can further examine and clarify these effects.

\section{Additional file}

Additional file 1: List of 34 deficits for constructing Frailty Index. (DOC $90 \mathrm{~kb}$ )

\begin{abstract}
Abbreviations
$25(\mathrm{OH})$ D: 25-hydroxyvitamin D; ANOVA: Analysis of variance; CART: Classification and regression tree; FI: Frailty Index; ROC: Receiver operating characteristic
\end{abstract}

\section{Acknowledgements}

This material is the result of work supported with resources and the use of facilities of the Veterans Affairs Pacific Islands Health Care System, Honolulu, Hawaii. The contents do not necessarily represent the views of the Department of Veterans Affairs or the United States Government.

\section{Funding}

None.

\section{Availability of data and materials}

The data that support the findings of this study are not publicly available.

\section{Authors' contributions}

GK contributed to the conception and design, collected the data, conducted statistical analyses, contributed to interpretation of the data, drafted the manuscript, revised the manuscript critically for important intellectual content, read and approved the final manuscript. SI contributed to the conception and design, contributed to interpretation of the data, revised the manuscript critically for important intellectual content, read and approved the final manuscript. MT contributed to interpretation of the data, revised the manuscript critically for important intellectual content, read and approved the final manuscript.

\section{Ethics approval and consent to participate}

This study was approved by the Institutional Review Boards of Veterans Affairs Pacific Islands Health Care System. Consent for participate was not required as the data were anonymised and collected by a retrospective chart review.

Consent for publication

Not applicable.

\section{Competing interests}

The authors declare that they have no competing interests.

\section{Publisher's Note}

Springer Nature remains neutral with regard to jurisdictional claims in published maps and institutional affiliations.

\section{Author details}

${ }^{1}$ Department of Primary Care and Population Health, University College London (Royal Free Campus), Rowland Hill Street, London NW3 2PF, UK.

${ }^{2}$ Veterans Affairs Pacific Islands Health Care System, Honolulu, Hawaii, USA. 
Received: 2 December 2016 Accepted: 8 October 2017 Published online: 16 October 2017

\section{References}

1. Wahl DA, Cooper C, Ebeling PR, Eggersdorfer M, Hilger J, Hoffmann K, Josse R, Kanis JA, Mithal A, Pierroz DD, et al. A global representation of vitamin D status in healthy populations. Arch Osteoporos. 2012;7:155-72.

2. Holick MF. Vitamin D deficiency. N Engl J Med. 2007;357(3):266-81.

3. Wimalawansa SJ. Non-musculoskeletal benefits of vitamin D. J Steroid Biochem Mol Biol. 2016;

4. Ross AC, Manson JE, Abrams SA, Aloia JF, Brannon PM, Clinton SK, DurazoArvizu RA, Gallagher JC, Gallo RL, Jones G, et al. The 2011 report on dietary reference intakes for calcium and vitamin D from the Institute of Medicine: what clinicians need to know. J Clin Endocrinol Metab. 2011;96(1):53-8.

5. Holick MF, Binkley NC, Bischoff-Ferrari HA, Gordon CM, Hanley DA, Heaney $\mathrm{RP}$, Murad MH, Weaver CM. Evaluation, treatment, and prevention of vitamin D deficiency: an Endocrine Society clinical practice guideline. J Clin Endocrinol Metab. 2011;96(7):1911-30.

6. Mayor S. Public Health England recommends vitamin D supplements in autumn and winter. BMJ. 2016:354:14061.

7. Grant WB, Karras SN, Bischoff-Ferrari HA, Annweiler C, Boucher BJ, Juzeniene A, Garland CF, Holick MF. Do studies reporting 'U'-shaped serum 25hydroxyvitamin D-health outcome relationships reflect adverse effects? Dermatoendocrinol. 2016;8(1):e1187349.

8. Grant WB. Critique of the U-shaped serum 25-hydroxyvitamin D leveldisease response relation. Dermatoendocrinol. 2009:1(6):289-93.

9. Davis CD. Vitamin D and health: can too much be harmful? Am J Lifestyle Med. 2009:3(5):407-8.

10. Garland CF, Kim JJ, Mohr SB, Gorham ED, Grant WB, Giovannucci EL, Baggerly L, Hofflich H, Ramsdell JW, Zeng K, et al. Meta-analysis of all-cause mortality according to serum 25-hydroxyvitamin D. Am J Public Health. 2014;104(8):e43-50.

11. Chowdhury R, Kunutsor S, Vitezova A, Oliver-Williams C, Chowdhury S, Kiefte-deJong JC, Khan H, Baena CP, Prabhakaran D, Hoshen MB, et al. Vitamin D and risk of cause specific death: systematic review and meta-analysis of observational cohort and randomised intervention studies. BMJ. 2014;348:91903.

12. Zittermann A, lodice S, Pilz S, Grant WB, Bagnardi V, Gandini S. Vitamin D deficiency and mortality risk in the general population: a meta-analysis of prospective cohort studies. Am J Clin Nutr. 2012;95(1):91-100.

13. Granic A, Aspray T, Hill T, Davies K, Collerton J, Martin-Ruiz C, von Zglinicki T, Kirkwood TB, Mathers JC, Jagger C. 25-hydroxyvitamin D and increased allcause mortality in very old women: the Newcastle $85+$ study. J Intern Med. 2015;277(4):456-67.

14. Melamed ML, Michos ED, Post W, Astor B. 25-hydroxyvitamin D levels and the risk of mortality in the general population. Arch Intern Med. 2008; 168(15):1629-37.

15. Visser M, Deeg DJ, Puts MT, Seidell JC, Lips P. Low serum concentrations of 25-hydroxyvitamin $D$ in older persons and the risk of nursing home admission. Am J Clin Nutr. 2006;84(3):616-22. quiz 71-2

16. Jia X, Aucott LS, McNeill G. Nutritional status and subsequent all-cause mortality in men and women aged 75 years or over living in the community. Br J Nutr. 2007:98(3):593-9.

17. Michaelsson K, Baron JA, Snellman G, Gedeborg R, Byberg L, Sundstrom J, Berglund L, Arnlov J, Hellman P, Blomhoff R, et al. Plasma vitamin D and mortality in older men: a community-based prospective cohort study. Am J Clin Nutr. 2010:92(4):841-8.

18. Sempos CT, Durazo-Arvizu RA, Dawson-Hughes B, Yetley EA, Looker AC, Schleicher RL, Cao G, Burt V, Kramer H, Bailey RL, et al. Is there a reverse Jshaped association between 25 -hydroxyvitamin D and all-cause mortality? Results from the U.S. nationally representative NHANES. J Clin Endocrinol Metab. 2013:98(7):3001-9.

19. Dror Y, Giveon SM, Hoshen M, Feldhamer I, Balicer RD, Feldman BS. Vitamin $D$ levels for preventing acute coronary syndrome and mortality: evidence of a nonlinear association. J Clin Endocrinol Metab. 2013;98(5):2160-7.

20. Durup D, Jorgensen HL, Christensen J, Schwarz P, Heegaard AM, Lind B. A reverse J-shaped association of all-cause mortality with serum 25hydroxyvitamin D in general practice: the CopD study. J Clin Endocrinol Metab. 2012;97(8):2644-52.

21. Zittermann A, Prokop S, Gummert JF, Borgermann J. Safety issues of vitamin D supplementation. Anti Cancer Agents Med Chem. 2013;13(1):4-10.
22. Korgavkar K, Xiong M, Weinstock MA. Review: higher vitamin D status and supplementation may be associated with risks. Eur J Dermatol. 2014;24(4): 428-34.

23. Kojima G. Prevalence of frailty in nursing homes: a systematic review and meta-analysis. J Am Med Dir Assoc. 2015;16(11):940-5.

24. Kojima G, Tamai A, Masaki K, Gatchell G, Epure J, China C, Ross GW, Petrovitch $\mathrm{H}$, Tanabe M. Prevalence of vitamin D deficiency and association with functional status in newly admitted male veteran nursing home residents. J Am Geriatr Soc. 2013;61(11):1953-7.

25. Kojima G, Tanabe M, Masaki K, Ross GW, Tamai A, Petrovitch H, Gatchell G, Fujii D. Association between depressive symptoms and vitamin $D$ deficiency in recently admitted nursing home residents. J Am Geriatr Soc. 2016;64(4):893-5.

26. Clegg A, Young J, lliffe S, Rikkert MO, Rockwood K. Frailty in elderly people. Lancet. 2013;381(9868):752-62.

27. Kojima G. Frailty as a predictor of future falls among community-dwelling older people: a systematic review and meta-analysis. J Am Med Dir Assoc. 2015;16(12):1027-33.

28. Kojima G. Frailty as a predictor of fractures among community-dwelling older people: a systematic review and meta-analysis. Bone. 2016;90:116-22.

29. Kojima G. Frailty significantly increases the risk of fractures among middleaged and older people. Evid Based Nurs. 2017;20(4):119-20.

30. Kojima G. Frailty as a predictor of hospitalisation among communitydwelling older people: a systematic review and meta-analysis. J Epidemiol Community Health. 2016;70(7):722-9.

31. Kojima G. Frailty as a predictor of nursing home placement among community-dwelling older adults: a systematic review and meta-analysis. J Geriatr Phys Ther. 2016;

32. Kojima G, Taniguchi Y, lliffe S, Walters K. Frailty as a predictor of Alzheimer disease, vascular dementia, and all dementia among community-dwelling older people: a systematic review and meta-analysis. J Am Med Dir Assoc. 2016:17(10):881-8

33. Kojima G. Frailty as a predictor of disabilities among community-dwelling older people: a systematic review and meta-analysis. Disabil Rehabil. 2016:1-12.

34. Kojima G, lliffe S, Jivraj S, Walters K. Association between frailty and quality of life among community-dwelling older people: a systematic review and meta-analysis. J Epidemiol Community Health. 2016;70(7):716-21.

35. Mitnitski AB, Mogilner AJ, Rockwood K. Accumulation of deficits as a proxy measure of aging. ScientificWorldJournal. 2001;1:323-36.

36. Searle SD, Mitnitski A, Gahbauer EA, Gill TM, Rockwood K. A standard procedure for creating a frailty index. BMC Geriatr. 2008;8:24.

37. Kojima G, Tanabe M. Frailty is highly prevalent and associated with vitamin D deficiency in male nursing home residents. J Am Geriatr Soc. 2016;64(9):e33-5.

38. Rockwood K, Andrew M, Mitnitski A. A comparison of two approaches to measuring frailty in elderly people. J Gerontol A Biol Sci Med Sci. 2007;62(7): 738-43.

39. Breiman L, Friedman J, Stone CJ, Olshen RA. Classification and regression trees. USA: CRC press; 1984.

40. Przybelski R, Agrawal S, Krueger D, Engelke JA, Walbrun F, Binkley N. Rapid correction of low vitamin D status in nursing home residents. Osteoporos Int. 2008;19(11):1621-8.

41. Zheng Y, Zhu J, Zhou M, Cui L, Yao W, Liu Y. Meta-analysis of long-term vitamin D supplementation on overall mortality. PLoS One. 2013;8(12):e82109.

42. Shab-Bidar S, Bours S, Geusens PP, Kessels AG, van den Bergh JP. Serum 25 $(\mathrm{OH}) \mathrm{D}$ response to vitamin D3 supplementation: a meta-regression analysis. Nutrition. 2014:30(9):975-85.

43. Gahche J, Bailey R, Burt V, Hughes J, Yetley E, Dwyer J, Picciano MF, McDowell M, Sempos C. Dietary supplement use among U.S. adults has increased since NHANES III (1988-1994). NCHS Data Brief. 2011;(61):1-8.

44. Enko D, Fridrich L, Rezanka E, Stolba R, Ernst J, Wendler I, Fabian D, Hauptlorenz S, Halwachs-Baumann G. 25-hydroxy-vitamin D status: imitations in comparison and clinical interpretation of serum-levels across different assay methods. Clin Lab. 2014;60(9):1541-50. 